\title{
Portugal Elementar
}

\author{
Antonio Joaquín Franco-Mariscal, ${ }^{* 1}$ María José Cano-Iglesias ${ }^{2}$
}

Este trabalho apresenta uma actividade de Quimica inovadora e simples para estudantes do Ensino Secundário que permite descobrir o nome dos distritos e das regiões autónomas de Portugal partindo dos símbolos químicos dos elementos da Tabela Periódica.

Palavras chave: ensino secundário, inovação educativa, elementos químicos, símbolos químicos, Portugal

A actividade consiste em identificar o nome de cada distrito ou região autónoma de Portugal no mapa da figura abaixo partindo do conjunto de elementos químicos que se apresentam como pista. Para tal segue os seguintes passos:

- Primeiro identifica os símbolos correspondentes aos elementos químicos que aparecem associados a cada distrito. Em caso de dúvida podes consultar uma Tabela Periódica.

- Uma vez identificados, coloca esses símbolos nos espaços disponíveis ordenando-os de forma a obter o nome de cada distrito ou região. Nalguns casos, para ajudar, colocaram-se algumas das letras que formam esses nomes.

Confirma, com o exemplo que se segue, como resolver esta actividade.

Resolve a ACtividAde e ReCorda a geografia de Portugal!

_ $\mathrm{R}_{\text {_ }} \mathrm{G}_{\text {_ _ }}$ (fósforo, oxigénio, trítio, urânio, alumínio) é um país situado no sudoeste da _ $\mathrm{R}_{-}{ }_{-}$ (oxigénio, protactínio, európio), na zona Ocidental da Península lbérica. É limitado a norte e a leste pelo reino de _ _ _ _ $\mathrm{A}$ (hidrogénio, azoto, einsténio, protactínio) e a sul e oeste pelo Oceano _ L $\hat{A}_{\text {_ _ _ _ _ }}$ (astato, cobalto, azoto, titânio). Então, PORTUGAl é um país da EuROPa que é limitado a norte e a este por EsPaNHA e a sul e oeste pelo Oceano AtLÂNTiCo.

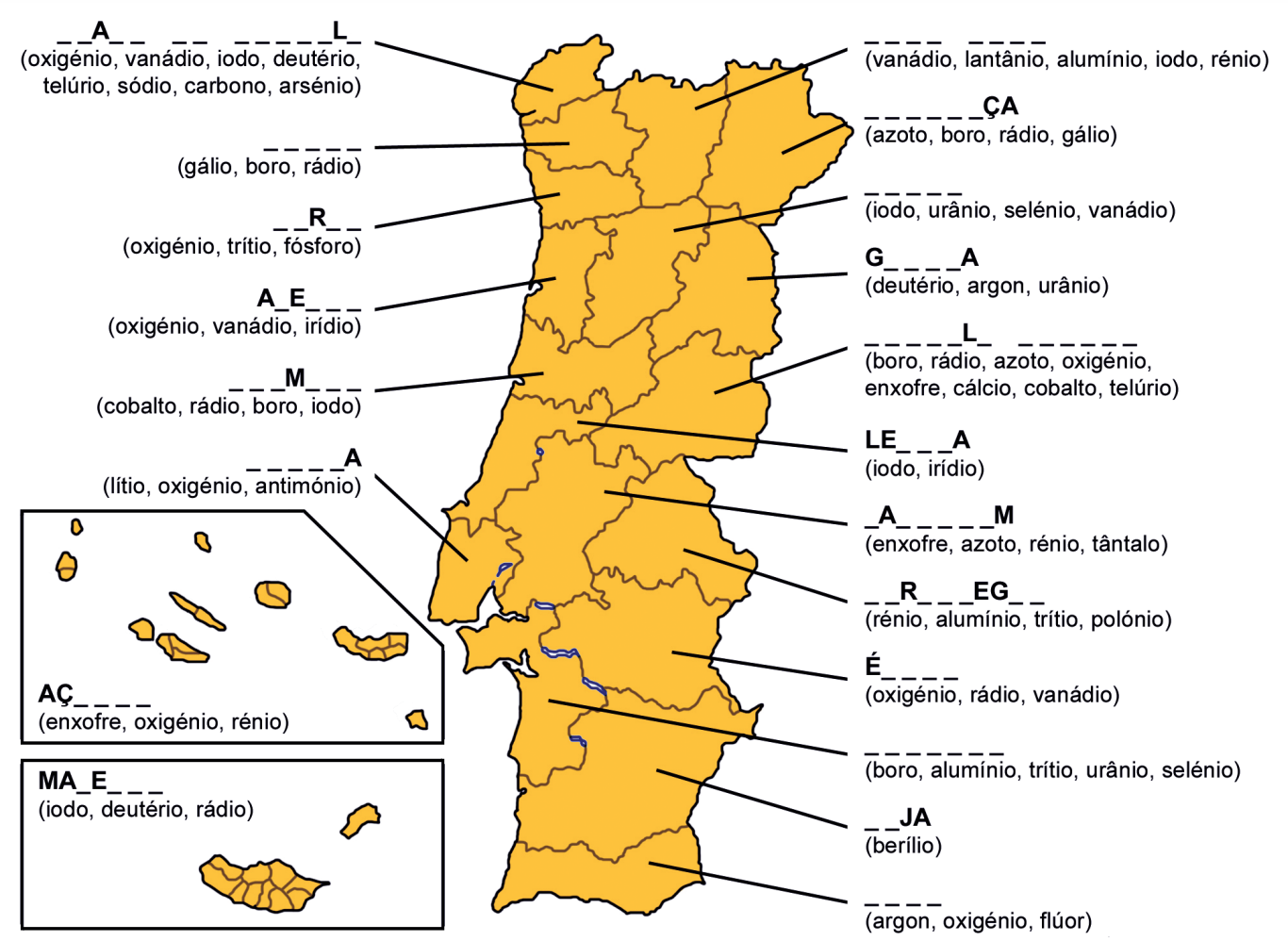

${ }^{* 1}$ Instituto de Educación Secundaria Javier de Uriarte AGRADECIMENTOS

Rota, Cádiz, Espanha - antoniojoaquin.franco@uca.es

2 Escuela Superior de Ingeniería, Departamento de In- Os autores agradecem ao Editor a ajuda prestada de forma desinteressada na geniería Mecánica y Diseño Industrial, Universidad de tradução do artigo para Português.

Cádiz, Cádiz, Espanha 


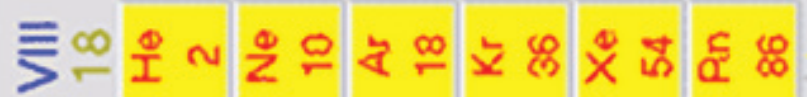

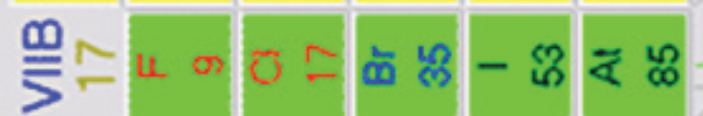

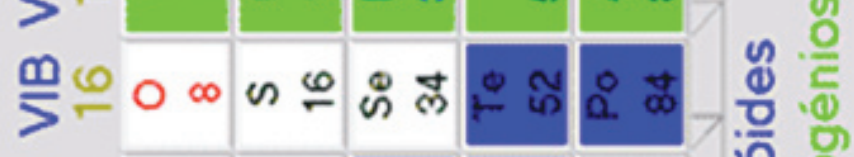

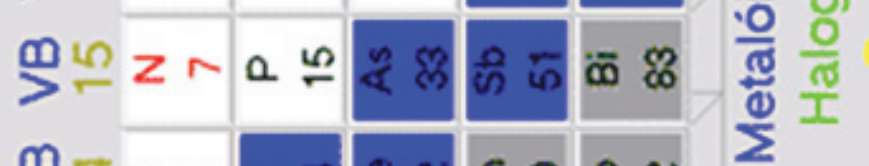

उ즈요 응

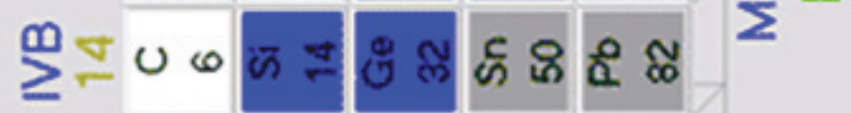

우울워 으

태울흐

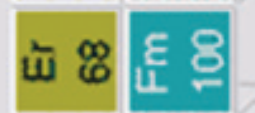

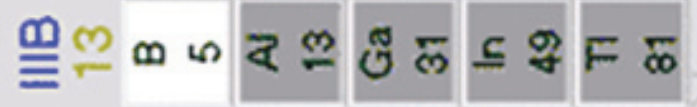

오는

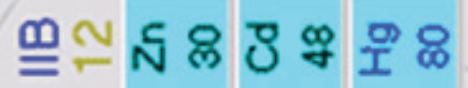

วั\&

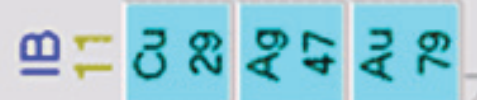

คํํ응

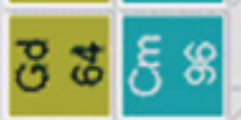

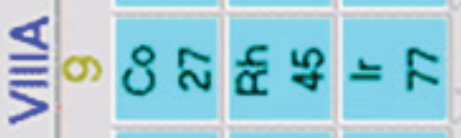

구요욜

员

है ญ ? के

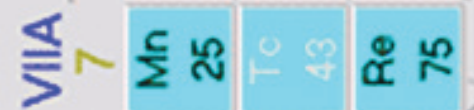

ह. 응

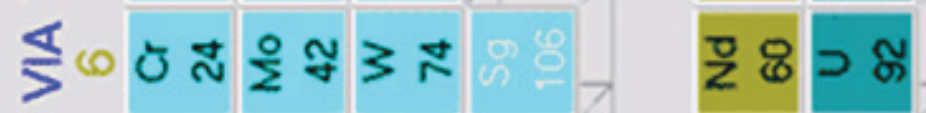

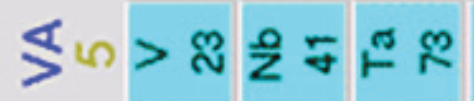

ลัด ถ์

\レトลกタะล

ช :

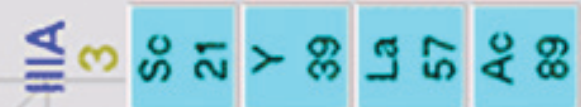

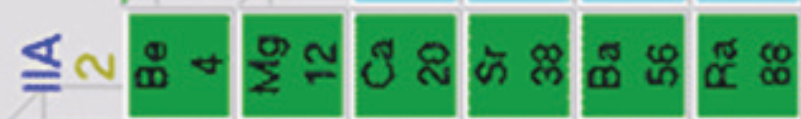

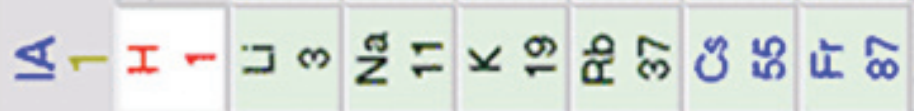

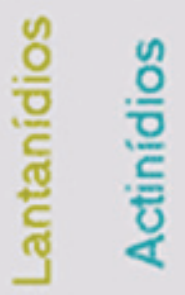

$-N \infty \pi N$ 